\title{
REVIEWS
}

\section{The menopause and its treatment in perspective}

\author{
F Al-Azzawi
}

Gynaecology Research Unit, Department of Obstetrics and Gynaecology, Robert Kilkpatrick Clinical Sciences Building, Leicester Royal Infirmary, Leicester LE2 7LX, UK

Correspondence to: $\mathrm{Mr}$ Farook Al-Azzawi fa2@leicester.ac.uk

Submitted 14 January 2000 Accepted 22 June 2000
The menopause, the last menstrual period, marks the end of a continuum of declining physiological fertility. Decreased fertility in relative or absolute terms antedates the menopause by $10-15$ years. The climacteric is the period of time (about 4-5 years) around the menopause during which ovarian function is gradually compromised. By the turn of the 20th century life expectancy in women of the Western world was about 58 years, at present it is about 82 , but as the mean age of the menopause, 51 years, has not changed more than one third of a woman's life is expected beyond the menopause. This is the first time in human history where long postmenopause existence is witnessed on such a scale. More importantly, the disability-free life expectancy, between the ages of 50 and 60 , for the whole population, largely due to cardiovascular disease and arthritis, has not changed over the last 30 years. ${ }^{1}$ For either gender, ageing is the primary factor influencing disabilities related to cardiovascular disease, arthritis, Alzheimer's disease, visual and hearing problems. As far as women are concerned it is expected that more such disabled women will live after the menopause, which is increasingly found to be a confounding variable and the treatment of which may profoundly influence the clinical progress of such disabilities. With the expected increase in postmenopausal population over the next 30 years, the health issues modulated by the menopause have moved from a peripheral medical interest into a central health care programme that commands a different strategy for resource allocation and for service delivery.

\section{Pathophysiology of the menopause}

From the age of 35 years onwards there is a progressive increase in the level of follicle stimulating hormone indicating a reduced amount of effective oestradiol and inhibin B production. ${ }^{2}$ In an elegant study, which combined data from other reports, the ovarian content of primordial follicles sustains a sharp decline at about the age of 37 (see fig 1). ${ }^{34}$

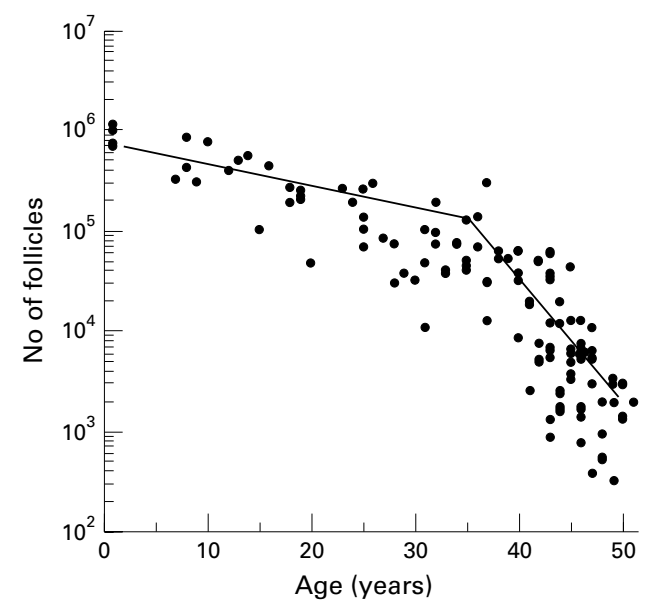

Figure 1 Biexponential model of declining number of follicles in pairs of human ovaries (age 0-51); adapted from Faddy et al.

hypergonadotrophic state, steroidogenesis continues in the ovarian stroma and theca cells, with an increased production of androgens, particularly androstenedione and testosterone, and to a lesser extent dehydroepiandrosterone and its sulphate (DHEA and DHEAS), which are peripherally converted into oestrone, the predominant albeit weak circulating oestrogen in the postmenopause.

Effects of oestrogen deficiency (see box 1) CENTRAL NERVOUS SYSTEM

The ubiquitous distribution of the oestrogen receptors in many parts of the central nervous system $^{5}$ may explain the wide spectrum of symptoms, which result from oestrogen deprivation. Oestrogens regulate the synthesis and the rate of release of many neuropeptides, neurotransmitters, and particularly the noradrenergic transmission in the medulla oblongata and the hypothalamus. Oestrogen increases sensory perception, locomotor activity, limb coordination, and balance. ${ }^{6}$ Oestrogen deficiency reduces serotonin synthesis in the brain, which may contribute to the development of insomnia. ${ }^{7}$ In addition oestrogen replacement treatment has been associated with a reduction in the incidence of Alzheimer's disease. ${ }^{9}{ }^{10}$ mordial follicles not occur, could menstruation be predicted to continue until the age of 70 ?

The source of oestradiol and inhibin B is the granulosa cell layer, which lines the growing primordial follicles. As the number of gonadotrophin responsive primordial follicles decline, and consequently the number of growing granulosa cells, symptoms and signs of oestrogen deficiency start to develop, although the dramatic biochemical and tissue structural changes in women appear soon after the menstrual periods cease completely. Due to the
VASOMOTOR SYMPTOMS

One of the immediate effects of oestrogen deficiency is the instability of the thermoregulatory centre located in the hypothalamus with the consequent development of hot flushes and sweating (vasomotor symptoms). The hot flush results from sudden vasodilatation of skin capillaries, which typically affects the chest area and spreads upward to the facial skin; there is 


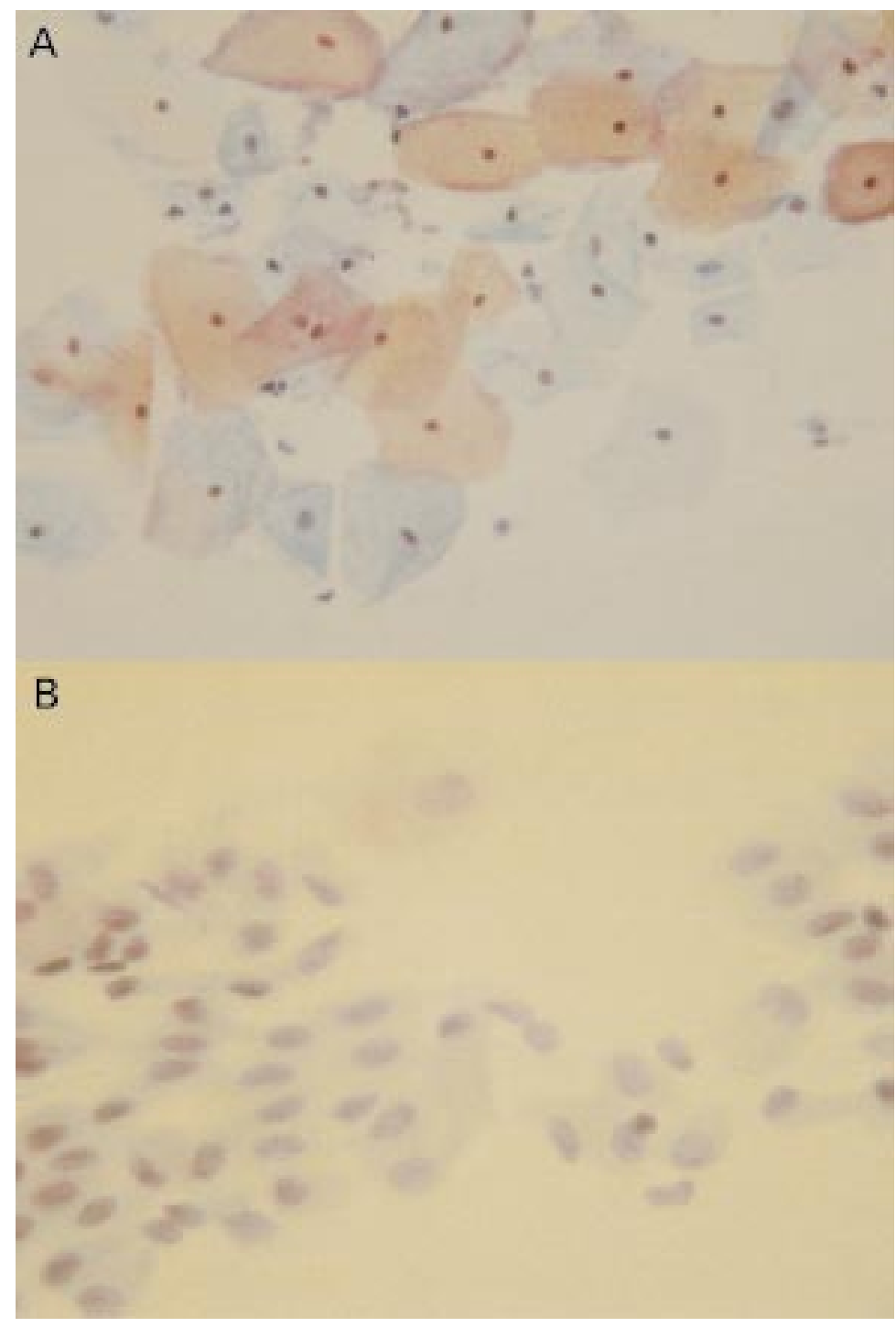

Figure 2 Vaginal cytology: $(A)$ the effect of oestrogen is demonstrable by the abundance of large flat squamous epithelial cells, with acidophillic cytoplasm and relatively small nuclei. In contrast to the vaginal smear obtained from oestrogen deficient woman (B) where parabasal cells dominate the picture, with small rounded cells containing large nuclei surrounded by scanty basophilic cytoplasm.

an increase in skin temperature by about $1-2^{\circ} \mathrm{C}$. This hot flush lasts for less than a minute and is usually followed by perspiration. The majority of women experience vasomotor symptoms of varying degrees of frequency and severity, and as many as $25 \%-50 \%$ will continue to suffer from these symptoms at five years after the menopause. The quality of life may be severely compromised by the presence of menopausal symptoms, which are easily cured by hormone replacement therapy (HRT). It is essential to appreciate that the absence of vasomotor symptoms does not reflect a lesser susceptibility to develop the degenerative changes elsewhere in the body as a result of the menopause.

\section{UROGENITAL AGEING}

The loss of oestrogen supply affects the lower genital tract. This results in thinning of the vaginal epithelium (fig 2), and reduction in vaginal transudates, which causes vaginal
Box 1: Symptoms associated with the climacteric and postmenopausal years ACUTE CONSEQUENCES OF OESTROGEN DEFICIENCY

Vasomotor symptoms

- Hot flushes.

- Sweats.

- Insomnia.

- Palpitations.

Psychological symptoms

- Mood changes.

- Anxiety.

- Loss of memory.

- Loss of concentration.

- Irritability.

Reproductive tract symptoms

- Vaginal dryness.

- Loss of libido.

- Dyspareunia.

Urinary symptoms and urethral syndrome CHRONIC CONSEQUENCES OF OESTROGEN DEFICIENCY

- Skeletal disease: osteoporosis.

- Cardiovascular diseases and strokes.

dryness and dyspareunia. There is also reduction in the supporting collagen.

A decrease in cervical mucus may further contribute to the symptom of vaginal dryness. The endometrium becomes atrophic. Ligamentous support to the uterus, cervix, and vagina undergo atrophy, which may present clinically as genital prolapse.

Atrophy of the urothelium of the trigone of the bladder and of the urethra makes these areas more sensitive to the irritating effect of urine, causing urgency, frequency, and dysuria.

SKIN

As a result of the ageing process as well as hypo-oestrogenaemia, the skin sustains a reduction in the amount of collagen with thinning of the dermis and consequently promotes the development of wrinkles and appearance of lines. The use of oestrogen increases dermal thickness mainly due to an increase in collagen thickness, which retains more water. ${ }^{11}{ }^{12}$

BONE METABOLISM

Increased osteoclastic activity supervenes within 6-8 weeks of the loss of oestrogen, and as a result a number of biochemical changes may be observed:

- Reduction in serum level of osteocalcin.

- Increase in urinary hydroxyproline: creatinine ratio.

- Increase in renal leakage of calcium.

- Reduction in intestinal absorption of calcium.

\section{Osteoporosis}

Osteoporosis is a condition marked by a reduction in bone mass, either due to reduced bone formation or accelerated bone resorption. Bone remodelling is a continuous process of resorption and bone formation, with activated 

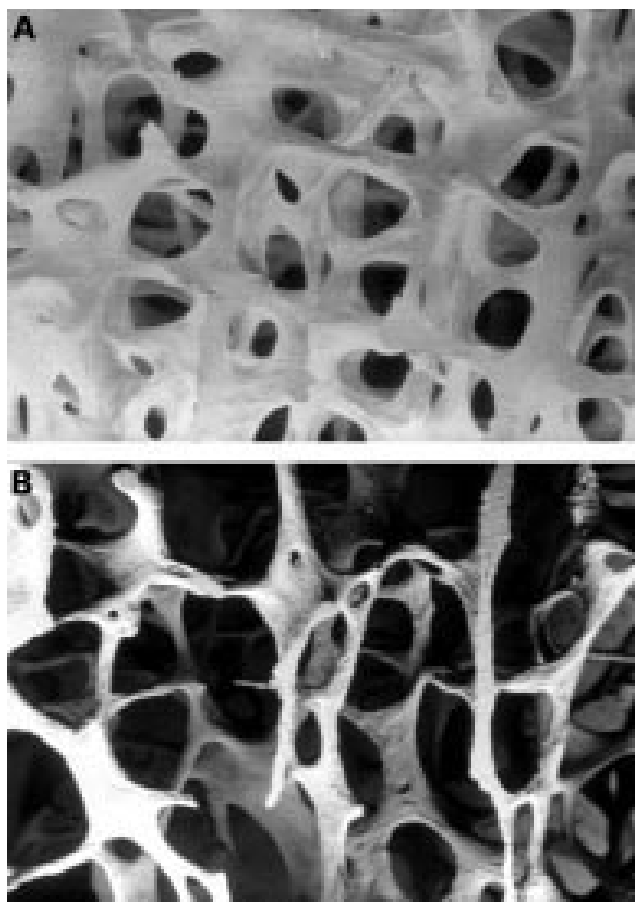

Figure 3 (A) Scanning electron micrograph showing bone architecture in health and $(B)$ in osteoporosis with thinning and loss of trabeculae; from Atlas of Osteoporosis by $\mathcal{F} C$ Stevenson and M S Marsh, Parthenon Publishing Group, 1993; published with permission.

bone resorption being the main feature of oestrogen deficiency. The main morphological change in osteoporosis is the loss of collagenous framework, which constitutes the bone microarchitecture (fig 3). In the postmenopausal population it is manifested by a progressive reduction in height, development of dorsal kyphosis (dowager's hump), and by the high incidence of low trauma fractures of the distal radius, vertebral compression, and fractures of the neck of the femur.

The life time risk of osteoporotic fractures for a 50 year old white man is $2 \%$ for vertebral fractures, $2 \%$ for distal radius fracture, and 3\% for femoral neck fractures; the corresponding figures for a woman of the same age and ethnicity are $11 \%, 13 \%$, and $14 \%$, respectively. ${ }^{13}$ Therefore, more than one third of women will sustain one or more osteoporotic fracture in their lifetime. The maximum bone mass is attained at the age of 30 , followed by a plateau for 5-10 years, whereafter age related bone loss of about $0.5 \%$ per annum, ensues. ${ }^{14}{ }^{15}$ At the menopause, a phase of accelerated bone loss of about $4 \%$ per annum has been recognised, which affects mainly cancellous bones, and lasts for about four years. ${ }^{14}{ }^{16}$ Afterwards, the annual rate of bone loss slows back to $1 \% .{ }^{17}$ By the age of 80 , a non-hormonally replaced woman will have lost $30 \%-50 \%$ of her bone mass. A reduction of bone density by 1 standard deviation (SD), in the hip for example, increases the risk of hip fractures by 2.6 -fold. ${ }^{18}$ Femoral neck fractures carry a $15 \%$ fatality within three months and are associated with a high disability rate in survivors. Women of north western European extraction, Asian, and oriental women accrue a lower bone density during their lifetime and are therefore

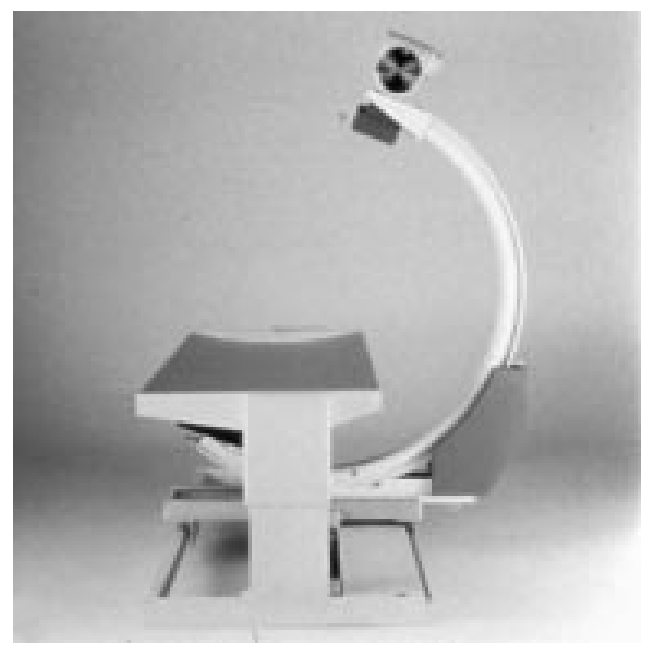

Figure 4 Dual energy $x$ ray absorptiometry (DEXA; Expert Machine, Lunar Inc).

more susceptible to osteoporosis after the menopause, when compared with AfroCaribbean or Mediterranean women.

Oestrogen effects on bone metabolism

- Reduction in interleukin-1 and interleukin-6 production in bone remodelling units. ${ }^{19}$

- Induction of apoptosis in osteoclasts. ${ }^{20}$

- Stimulation of bone formation by the increased production of insulin-like growth factor (IGF)-I, IGF-II, and transforming growth factor- $\beta .^{21}$

- Increased synthesis of calcitonin. ${ }^{22}$

- Increased vitamin D receptor expression in osteoblasts. ${ }^{23}$

\section{Measurement of bone mass}

Osteoporosis is an asymptomatic disease until its late stages, and therefore early detection is necessary to prevent its development. There are several techniques to measure bone mass which include ultrasound scan of the os calcis, single energy absorptiometry, dual energy $x$ ray absorptiometry (DEXA; see fig 4), and computed tomography. The quantitative ultrasound method may be suitable for screening to predict osteoporotic fracture risk, ${ }^{24}{ }^{25}$ but may have limitations in the follow up assessment of response to treatment. Computed tomography, while providing a volumetric assessment of bone density, has the disadvantage of high radiation dose and high costs. The single energy $x$ ray absorptiometry offers high precision with a low dose of radiation at appendicular sites-namely, the distal radius and os calcis. DEXA allows measurements of bone mineral density (BMD) at the spine, hip, total body, and at the appendicular sites, and offers a more precise measurements by allowing for soft tissue interference.

The organic matrix of bone is impregnated with calcium salts in the form of hydroxyapatite. The bone mineral content correlates with the mechanical strength of bone, and is usually measured by its estimation per unit area in the bone examined: BMD, expressed as $\mathrm{g} / \mathrm{cm}^{2}$.

Since bone mass is nearly normally distributed in a given healthy population, at peak bone mass it has become customary to express 
Box 2: Causes of osteoporosis

Metabolic and endocrine aetiology

- Hypogonadism.

- Hyperadrenocorticism.

- Thyrotoxicosis.

- Hyperparathyroidism.

Nutritional deficiencies

- Vitamin D deficiency.

- Alcoholism.

- Malabsorption syndrome.

- Chronic liver disease.

Drug induced

- Chronic corticosteroids use.

- Chronic heparin therapy.

BMD in terms of SD units around the mean. A threshold range for osteopenia is a BMD between -1.0 to $-2.49 \mathrm{SD}$ units and the threshold for osteoporosis is a BMD lower than -2.5 SD units below that of young healthy adults ( $\mathrm{T}$ score). When the number of SD units, which denote the $\mathrm{BMD}$, is compared to age matched control, the $\mathrm{Z}$ score is derived (figs 5 and 6). Upon the diagnosis of osteoporosis causes other than oestrogen deficiency should be considered and appropriate investigations instituted (box 2).

CARDIOVASCULAR SYSTEM

Oestrogen deficiency results in several changes in the cardiovascular system:

Heart

Ischaemic heart disease (IHD) is the most common cause of death in women over the age of 55, and accounts for about $25 \%$ of deaths. The menopause is an independent risk factor for IHD, the overall relative risk for IHD in the menopause is 2.7 and this risk rises with younger age at menopause. ${ }^{26}$ In women with a previous myocardial infarction, ever-use of oestrogen significantly reduces age adjusted

\section{Bone densitometry \\ Menopause Research Unit \\ Leicester Royal Infirmary}

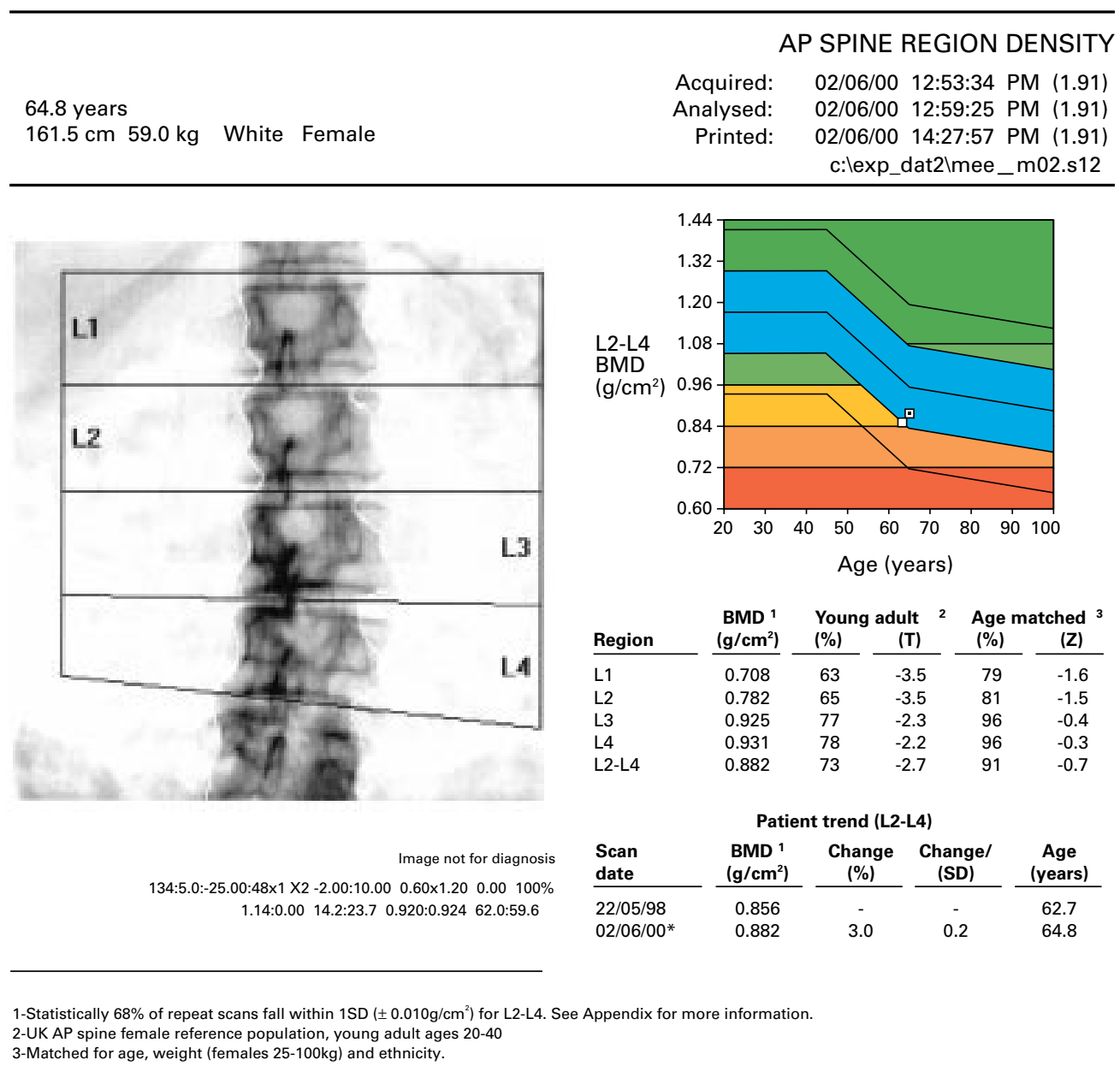

Comments:

Internal hydroxyapatite standard $=\mathbf{0 . 9 2 4}$

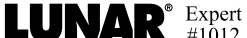

Figure 5 Bone densitometry results of osteoporotic lumbar spines with the second reading marked by the dotted square ( $\cdot$ ) two years thence. Follow up DEXA is necessary after the instigation of treatment to document response. 


\section{Bone densitometry \\ Menopause Research Unit \\ Leicester Royal Infirmary}

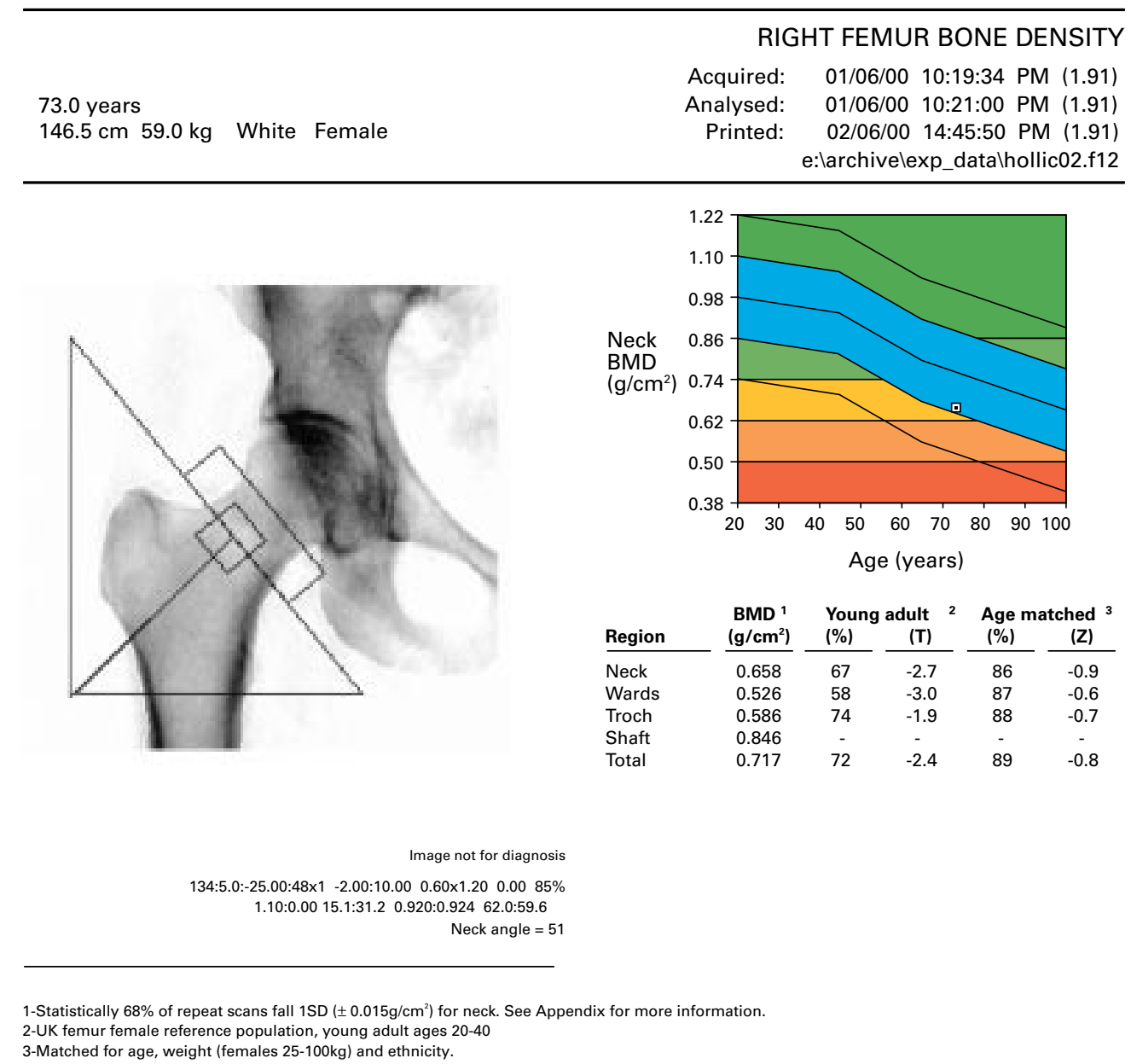

\section{Comments:}

Internal hydroxyapatite standard $=\mathbf{0 . 9 2 4}$

IUNAR Expert

Figure 6 Bone densitometry of the femur.

mortality from a repeat myocardial infarction to 0.56 (95\% confidence interval (CI) 0.50 to $0.61) .{ }^{27}$ The relative risk for cardiovascular disease in women on oestrogen replacement remains 0.65 even after adjustment for other risk factors: previous myocardial infarction, diabetes, hypertension, smoking, cholesterol, body mass index, age, education. ${ }^{28}$

There are structural and functional changes in the heart following the menopause:

- Reduced stroke volume. ${ }^{29}$

- Reduced cardiac output. ${ }^{30}$

- Left ventricular hypertrophy: posterior wall and septum thickness increases by $10 \%$ within five years after the menopause. ${ }^{31}$

- Higher incidence of "ischaemia minor" in the electrocardiograms of oophorectomised women. ${ }^{32}$

A reduction in the incidence of cardiovascular disease including cerebrovascular accidents, and will therefore have the greatest potential to influence the life expectancy of women. Preventing myocardial ischaemia, nonfatal infarctions, and cerebrovascular insufficiency ranks among the most important ways of increasing the "disability-free life expectancy" of women.

\section{Blood pressure}

The incidence of hypertension is significantly higher in hypo-oestrogenic postmenopausal women when compared with women receiving oestrogen replacement therapy after adjustment for age, race, and weight. ${ }^{33}$ Postmenopausal oestrogen replacement treatment reduces systolic and diastolic blood pressure in women, and this effect is not dose related. In addition, oestrogen reduces the stress induced rise in blood pressure. The arterial vasodilatory effect of oestrogen may be a crucial mechanism in modulating its cardiovascular protective effects, whether that is due to increased prostacyclin production, ${ }^{34}$ calcium channel blockade, ${ }^{35}$ or endothelium independent vasorelaxation. ${ }^{36}$ 


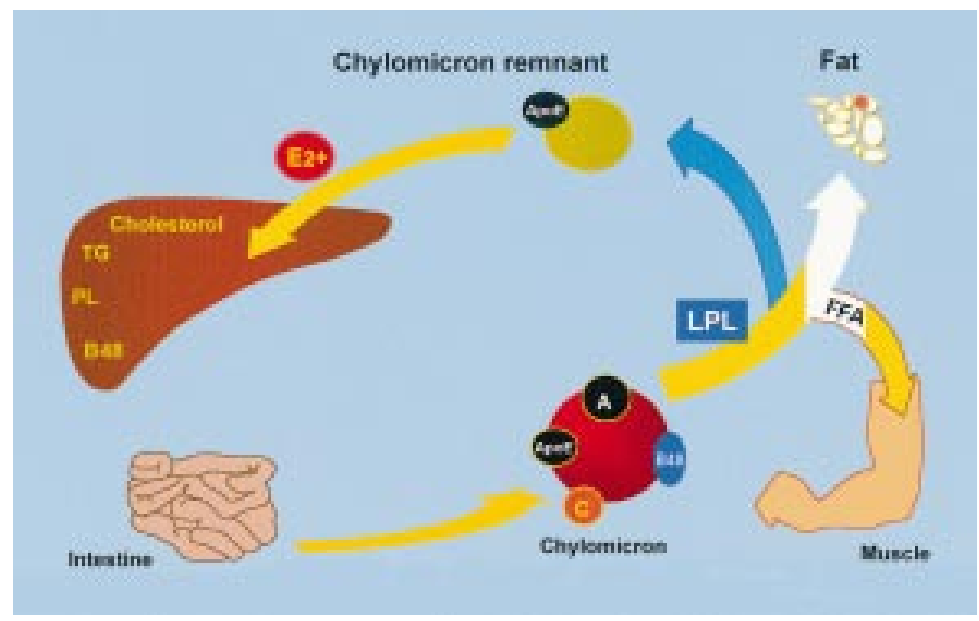

Figure 7 Lipoprotein metabolism: absorption of chylomicra initial liver handling and release to body tissues $(A p o E=$ apolipoprotein $E ; B 48=$ apolipoprotein $B 48 ; E 2=$ oestradiol, influences the adjacent process according to the annotated $+/-$ sign; FFA $=$ free fatty acids; $L P L=$ lipoprotein lipase; $P L=$ phospholipids; $T G=$ triglycerides).

The effect of oestrogen on blood pressure has been reported in many publications. A rise of blood pressure, as measured by the conventional sphygmomanometer, was documented by some $\mathrm{e}^{37}$ while others ascribed the rise to the type of oestrogen used..$^{38}$ Others failed to demonstrate a change in blood pressure with oestrogen therapy in normotensive or in hypertensive women. ${ }^{39} 40 \mathrm{~A}$ reduction in blood pressure was documented in a double blind cross over study of conjugated equine oestrogens and placebo. ${ }^{41}$ Automated ambulatory blood pressure measurement is a useful technique to overcome the problem of white coat hypertension, and gives a number of readings throughout a 24 hour period. In a comparative study that evaluated the mean change in daytime and night-time systolic and diastolic blood pressure in oophorectomised women there was a consistent drop in systolic and diastolic blood pressure during the day and night. This trend was statistically significant in women treated with transdermal oestradiol compared with oral oestrogen after six months of observation. ${ }^{42}$ After oral administration of oestrogen the induction of angiotensinogen through the first pass effect on the liver has been proposed but this was not substantiated in the literature. Certain gene polymorphisms may be responsible for the development of high blood pressure in some oestrogen users, however, this has not yet been documented.

Effects of oestrogens on blood vessels

Postmenopausal oestrogen therapy results in acceleration of blood flow in the aorta, ${ }^{43}$ reduced peripheral vascular resistance, ${ }^{44}$ and a significant increase in the pulsatility index in the carotid arteries. ${ }^{45}$

Postmenopausal oestrogen supplement delays the onset of exercise induced STdepression and improved exercise tolerance in women with angiographically confirmed coronary heart disease, ${ }^{46}$ and angiographic studies have shown a reduced coronary artery occlusion risk in oestrogen users. ${ }^{47}$

\section{Cerebrovascular effect of oestrogen}

A sex difference exists in cerebral blood flow being greater in the premenopause than in age matched males, but it declines to equality after the menopause. ${ }^{48}$ Oestrogen treatment in the postmenopause reduces resistance in the internal carotid artery ${ }^{45}$ and middle cerebral artery. ${ }^{49}$ In another study the use of unopposed oestrogen in women with established carotid

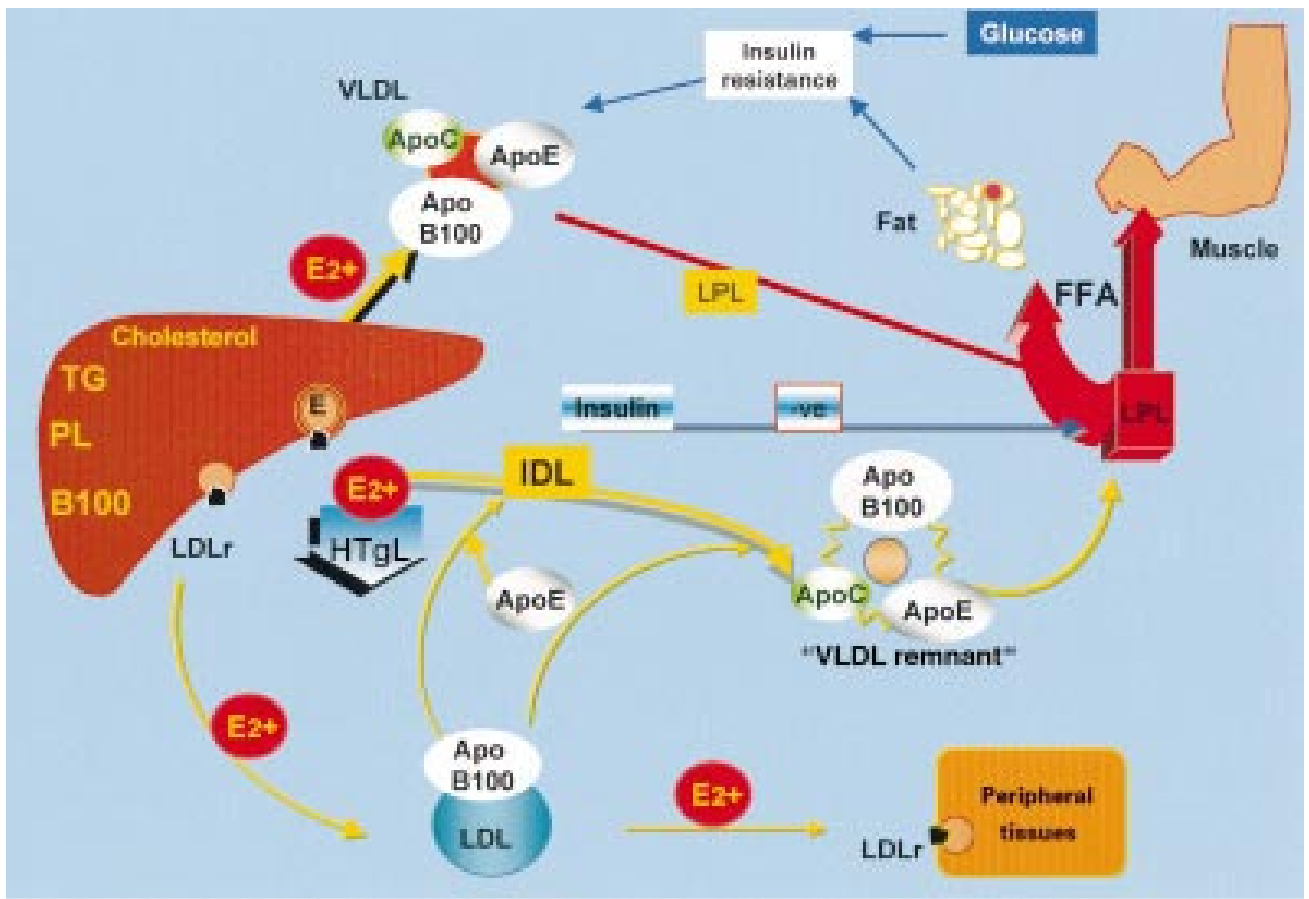

Figure 8 Lipoprotein metabolism: progressive degradation of the very low density lipoprotein (VLDL) molecule down to the low density lipoproteins $(A p o C / E=$ apolipoprotein $C / E ; B 100=$ apolipoprotein B100;E2 = oestradiol, influences the adjacent process according to the annotated $+/-$ sign; FFA = free fatty acids; $H T g L=$ hepatic triglyceride lipase; IDL $=$ intermediate density lipoprotein; $L D L=$ low density lipoprotein; $L D L r=$ low density lipoprotein receptor; $L P L=$ lipoprotein lipase; $P L=$ phospholipids; $T G=$ triglycerides). 


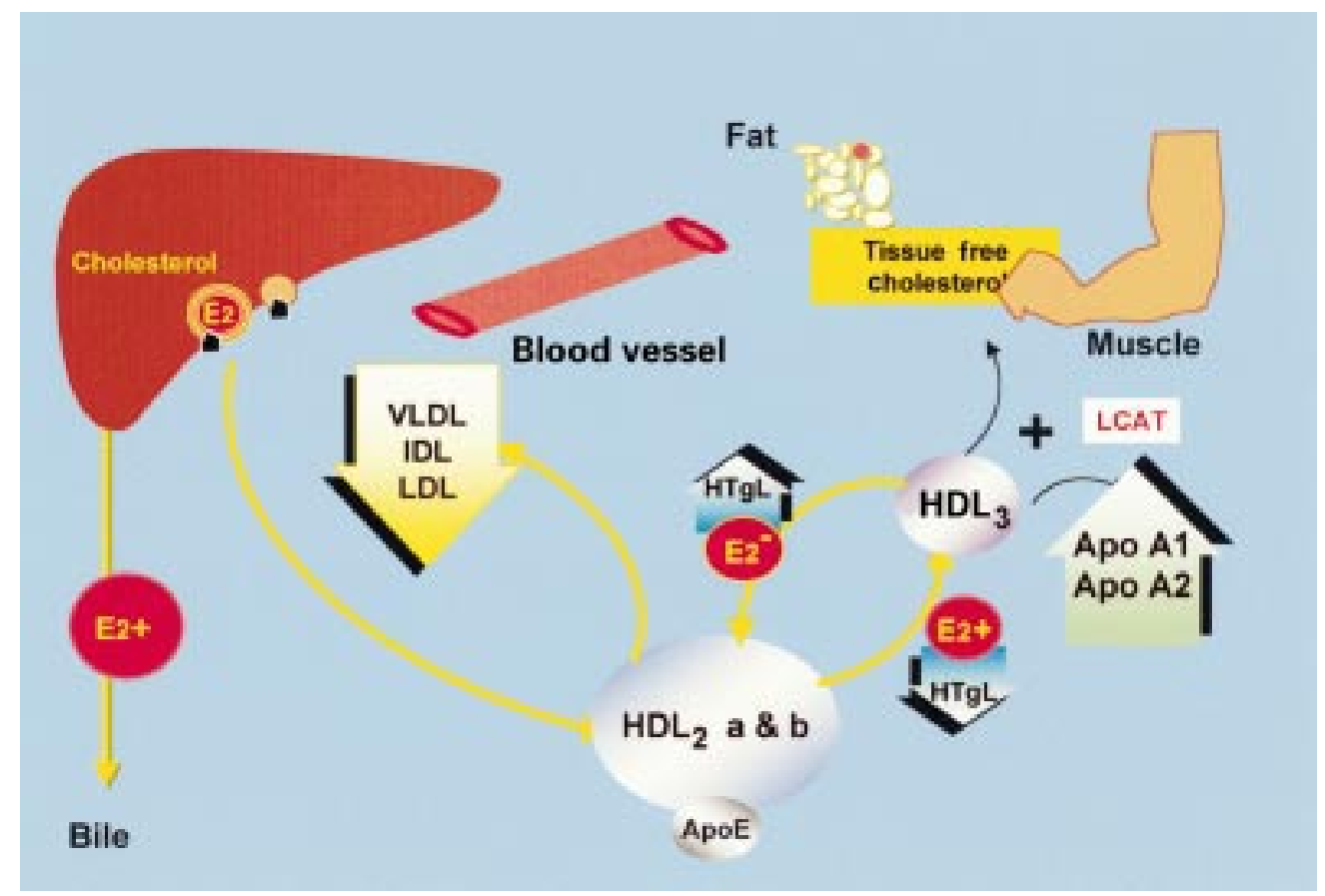

Figure 9 Lipoprotein metabolism: reverse cholesterol transport $(A p o A 1 / A 2 / E=$ apolipoprotein $A 1 / A 2 / E ; B 100=$ apolipoprotein B100;E2 = oestradiol, influences the adjacent process according to the annotated $+/-\operatorname{sign} ; H T g L=h e p a t i c$ triglyceride lipase; $H D L=$ high density lipoprotein $; I D L=$ intermediate density lipoprotein; $L C A T=$ lecithin cholesterol acyltransferase $[D L=$ low density lipoprotein; $L P L=$ lipoprotein lipase VLDL $=$ very low density lipoprotein).

artery atheromas resulted in a reduction of $28 \%$ plaque length and $18 \%$ of plaque thickness after six months of treatment. ${ }^{50}$

\section{Lipoprotein metabolism}

Lipid metabolism is a complex process, which involves mainly the liver, adipose tissue, skeletal muscles, and peripheral blood monocytes in addition to the intestinal villi (see figs 7,8 , and 9).

The disturbance in lipid metabolism ranks highly among the identified risk factors of atherosclerosis and cardiovascular disease. Raised serum total cholesterol and triglyceride concentrations have been identified to have a linear positive relationship, and high density lipoprotein (HDL)-cholesterol was found to have an inverse relationship to the risk of coronary heart disease.

There are sex differences in lipid profile, which in women is profoundly affected by hormonal changes. Before the menopause, women have a less atherogenic lipid profile, but the changes in lipoprotein metabolism in postmenopausal women have been associated with the increased cardiovascular mortality. This risk has been shown to decline with the lowering of serum cholesterol. ${ }^{51}$

After the menopause, women retain their higher level of HDL-cholesterol, but this is counteracted by a higher level of low density lipoprotein (LDL)-cholesterol than in men. About half the patients with coronary artery disease have reduced HDL-cholesterol levels; the commonest lipoprotein abnormality. Consequently, elevation of HDL-cholesterol by oestrogen treatment should be viewed as an important vehicle for the cardioprotection effect of this hormone. Oestrogen reduces LDL oxidation and therefore interferes with its uptake by monocytes and tissue macrophages, a particularly important step in the development of atherosclerosis. The significance of raised serum triglycerides as an independent risk factor for cardiovascular disease is still controversial. About $30 \%-50 \%$ of the cardioprotective effects of oestrogens has been attributed to the changes in LDL and HDL. When lipoprotein subfractions are analysed, a low risk profile is characterised by a low LDLcholesterol, and a raised HDL-cholesterol, particularly the $\mathrm{HDL}_{2}$ subfraction, while the level of the LDL-cholesterol is positively related to the risk of IHD. ${ }^{51}$

Apoproteins are important for the transport of lipids and their uptake in peripheral tissues, and are important independent predictors of cardiovascular disease risk. Epidemiological data have linked apoprotein B (Apo B) with cerebrovascular disease while Apo A1 is inversely related to the risk. Lipoprotein a, Lp (a), has been identified as an independent risk factor for atherosclerosis and IHD, ${ }^{52}$ although the underlying mechanism has not yet been clearly defined. Oestrogen replacement treatment in postmenopausal women reduces $\mathrm{Lp}$ (a) levels. $^{53}$

An apparently beneficial effect of HRT on the risk of cardiovascular disease is probably mediated through a favourable effect on the lipid profile. In addition, oestrogen reduces central obesity, and together both reduce the insulin concentrations. Indeed, current oestrogen use may reduce the risk of non-insulin dependent diabetes mellitus by $20 \%$. $^{54}$

Oestrogen deficiency is associated with increase in total cholesterol, LDL-cholesterol, $\mathrm{Lp}(\mathrm{a})$, and reduction in HDL-cholesterol. ${ }^{55}$ Oestrogen replacement reverses these changes. Progestins may increase the activity of hepatic 
lipoprotein lipase and therefore increases the catabolism of $\mathrm{HDL}_{2}$, with the result of lowering the levels of $\mathrm{HDL}_{2}$ and HDL-cholesterol. ${ }^{56}$ In addition, oestrogen with cyclically administered progestogen has little or no effect on triglycerides. ${ }^{53}$ When a progestogen is used in a continuous combined fashion along with oestrogen, as an amenorrhoea regimen, HDL levels were reduced, however. ${ }^{57}$

CHANGES IN COAGULATION FACTORS

The menopause results in changes in coagulation factors, with increases in fibrinogen, ${ }^{58}$ plasminogen activator inhibitor-1 (PAI-1), ${ }^{59}$ factor VIIc, ${ }^{60}$ and antithrombin-III (AT-III). ${ }^{61}$ Oestrogen replacement treatment is associated with increases in plasminogen, platelet count, factor VII, factor IX, factor X, factor XI, protein C, and von Willebrand's factor. Oestrogen replacement treatment is associated with reductions in fibrinogen, AT-III, prothrombin time, tissue plasminogen activator, PAI-1, platelet aggregation time, and protein $S .{ }^{62}$

The interaction between these factors is also governed by a large buffering capacity to compensate, within limits, the effects of any derangement in individual protein. Thus the predictive value of future occurrence of venous thrombosis as a result of oestrogen replacement treatment, by measuring each individual clotting factor is restricted to the finding of gross abnormalities only. Therefore one has to rely on the epidemiological data, which have shown that there is a very small increase in the risk of venous thrombosis as a result of HRT use, an excess of 1:5000. ${ }^{63}{ }^{64}$ These studies suggest that the risk of venous thromboembolism is greater during the first year, which then declines over the following two years and becomes not significantly different from controls after three years of use. Patients found to have protein $\mathrm{S}$ deficiency, activated protein $\mathrm{C}$ resistance such as those with factor $\mathrm{V}$ Leiden gene phenotype, require careful assessment of the risks and benefits of HRT, which have to be considered and tailored to the individual needs before embarking on treatment.

\section{The HERS Study}

The Heart Estrogen/progestin Replacement Study (HERS) was a randomised placebo controlled study of continuous combined conjugated oestrogens $(0.625 \mathrm{mg})$ plus $2.5 \mathrm{mg}$ of medroxyprogesterone acetate for the secondary prevention of IHD in women with established diagnosis of IHD. ${ }^{65}$ In contrast to the investigators' expectation there was an increase of IHD events in the treated group compared with the placebo group during the first two years of the study. However, when the first two years were free from intercurrent IHD, there was a trend towards a beneficial effect in the treated group. ${ }^{66}$

This trial was a landmark in this field but unfortunately suffered from a number of pitfalls, which raised more questions than it could answer. The recruitment period was extended with the majority of patients enrolled towards the end of the 18 month period, and the observation time was thus reduced to a mean of 4.1 as opposed to 4.75 years in the initial description of the protocol. Moreover, the incidence of IHD events in the placebo group was $3.3 \%$, which is significantly lower than the expected incidence of $5 \%$. Such factors clearly undermine the statistical power of the study.

The study design lacked an oestrogen only group and included only one type of progestin. The choice of the progestin and the duration of its administration might have played another factor in the results of the HERS report. Medroxyprogesterone acetate has been shown to adversely affect coronary arteries in monkeys. ${ }^{67} 68$

The prothrombotic potential of women who experienced IHD events was not determined and in particular the geno typing for factor $\mathrm{V}$ Leiden. Factor V Leiden mutation has also been linked to arterial disease. ${ }^{69}$

\section{Diagnosis of the menopause}

The majority of postmenopausal women who present to their doctors requesting help are suffering from hot flushes and sweating and vaginal dryness. A few present wishing to prevent osteoporosis or coronary heart disease. The diagnosis of the menopause depends on the presence of typical symptoms (above), amenorrhoea for $>12$ months, or when the clinical picture is not as clear cut a serum level of follicle stimulating hormone in excess of 30 IU/1 confirms the diagnosis.

In women who are still menstruating, the differential diagnosis includes the premenstrual syndrome especially when associated with symptoms of the climacteric. Endogenous depression is another consideration in the differential diagnosis. Rarely, vasomotor symptoms may be associated with the carcinoid syndrome, pheochromocytoma or hyperthyroidism, but other manifestations and the characteristic biochemical changes associated with these three conditions should establish the relevant diagnosis.

Follicle stimulating hormone and oestradiol concentrations are not required for routine diagnosis, but they may be of help to establish the diagnosis of ovarian failure in atypical cases, in the follow up of incomplete response to treatment, or in the case of conserved ovaries after hysterectomy.

Assessment of ovarian reserve had been attempted to predict the diagnosis of the menopause using the clomiphene citrate challenge test $^{70}$ and the gonadotrophin releasing hormone agonist test, ${ }^{71}$ but these functional tests were not found to be reliable (see review by Gulekli et $a l^{72}$ ).

\section{Treatment of the menopause}

The principle of HRT involves the administration of oestrogen, which provides symptom relief, reverses the changes in calcium metabolism, and improves lipoprotein metabolism. Oestradiol and oestrone are fat soluble molecules and therefore not readily absorbed from the gut except if the steroid is micronised (particle size $<1 \mu$ ) or if the oestrogens are esterified to a carrier salt that makes them more water 
soluble. An example of the latter includes oestradiol valerate, which is quickly metabolised in the liver into oestradiol and valeric acid, 12-C fatty acid. Another example is ethinyl oestradiol but because of its resistance to intracellular $17 \beta$ dehydrogenase it exerts a sustained activity, and is therefore not a suitable preparation for postmenopausal HRT.

Oral administration of oestrogens is subjected to the first pass effect of the liver with rapid conjugation to glucoronates and sulphates. Oestradiol is rapidly converted to the weaker oestrone. Oral therapy usually succeeds in building up a satisfactory serum oestradiol levels. The transdermal preparations form a theoretically safer way to administer oestrogens but suffer from limitations of skin absorption in at least $50 \%$ of instances and in the potential of skin reactions to the adhesive material in the patch. Alternatively the application of oestradiol in gel formulation rubbed over the skin may overcome this; nevertheless, serum oestradiol levels may still be lower than with oral treatment. The subcutaneous insertion of oestradiol pellets involves a surgical procedure, associated with mounting high serum oestradiol levels, and as such is responsible for the development of tachyphylaxis in a large number of women. The vaginal route is effective in delivering oestrogens, useful when a restricted effect to the vagina is required; however, the type and dose of oestrogens used can result in significant serum levels.

The side effects of oestrogens are:

- Oral administration of oestrogen may cause nausea and gastric irritation.

- Breast tenderness, usually dose related, but it usually settles down within 3-4 months.

- Headaches may be aggravated.

The average daily doses of oestrogen depicted in table 1 are those derived from the literature for the provision of adequate control of symptoms. Box 3 lists measures for the prevention and treatment of osteoporosis. The dose may be increased to overcome residual vasomotor symptoms.
Box 3: Prevention and treatment of osteoporosis

(1) $H R T$

- Oestrogen: natural not synthetic.

Continuous not cyclical.

Minimum bone sparing dose.

- Progestins (in women with an intact uterus).

Cyclical: minimum 12 days, with the minimum endometrium protecting dose.

Continuous combined HRT.

(2) Non-oestrogen treatment of bone loss

- Calcitonin.

- Fluoride.

- Tibolone.

- Raloxifene (selective oestrogen receptor modulator).

- Bisphosphonates.

(3) Additional measures

- Weight bearing exercise.

- Adequate ultraviolet exposure.

- Vitamin D >400 IU daily.

- Dietary calcium intake $1 \mathrm{~g}$ daily.

- Stop smoking.

NEED FOR A PROGESTOGEN

The continuous administration of oestrogen causes progressive proliferation of the endometrium. Such stimulation may lead to the development of endometrial hyperplasia, or even carcinoma of the endometrium, ${ }^{73}$ and therefore oestrogen only therapy can be given safely only to women who have had a hysterectomy.

Over the last 40 years progestogens have been introduced to offset the effect of continuous oestrogen stimulation of the endometrium. A progestogen is administered cyclically for 12-14 days every month and this regimen is usually followed by menstrual discharge. Alternatively, the progestogen may be used continuously alongside the oestrogen, the aim being to induce amenorrhoea. There is a wide variation

Table 1 Drugs used for postmenopausal hormone replacement therapy

\begin{tabular}{lll}
\hline Oestrogen & Type & Average daily dose \\
\hline Oral & Micronised oestradiol & $2 \mathrm{mg}$ \\
& Conjugated oestrogens & $0.625 \mathrm{mg}$ \\
& Oestradiol valerate & $2 \mathrm{mg}$ \\
Transdermal & Piperazine oestrone sulphate & $0.625 \mathrm{mg}$ \\
& Oestradiol in adhesive matrix or reservoir patch & $50 \mu \mathrm{g}$ \\
Subcutaneous pellets & Oestradiol in a gel formulation & $2.5 \mathrm{~g}$ \\
Vaginal applications & Administered at six monthly intervals & $50 \mathrm{mg}$ \\
& These are administered daily for three weeks followed by twice weekly & \\
& administration to minimise unopposed oestrogen effect on the uterus & \\
& Oestriol cream & Average daily dose \\
& Oestradiol vaginal tablets & (sequential regimen) \\
Progestational agents & Conjugated equine oestrogen cream & $300 \mathrm{mg}$ \\
& & $1 \mathrm{mg}$ \\
& Micronised progesterone & $0.075 \mathrm{mg}$ \\
& 19-Nortestosterone derivatives & $0.150 \mathrm{mg}$ \\
& Norethisterone & $10 \mathrm{mg}$ \\
Lther synthetic compounds & Levonorgestrel & $10-20 \mathrm{mg}$ \\
Tibolone & Norgestrel & $2.5 \mathrm{mg}$ \\
Raloxifene & C-21 Progestin: dydrogesterone & $60 \mathrm{mg}$ \\
\hline
\end{tabular}


in bioavailability and individual tissue concentration of different progestogens, making it difficult to derive relative potencies between various compounds. This is also noted in the variation of the incidence and severity of adverse effects between different individuals.

The main adverse effects associated with the use of progestogens are:

- Unscheduled bleeding.

- The development of premenstrual tension type of symptoms: fluid retention, bloatedness, cyclical mastalgia, weight gain.

- Acne and seborrhoea.

Progesterone is poorly absorbed from the gut and by micronising the crystals (particle size $<1 \mu$ ) its absorption may be enhanced, but in view of the rapid deactivation it needs to be administered in divided doses, and is associated with poor cycle control. Hence, synthetic steroids with progestogenic activity have been introduced in clinical practice, which showed a better absorption and bioavailability compared with the natural progesterone. There are two main derivations for the synthetic progestins available: removal of the carbon atom from testosterone and placing an ethinyl group in the C-17 position, or by adding an acetyl group to position $\mathrm{C}-17$ of the progesterone molecule. The former group possesses higher androgenic activity than the latter but is associated with a better menstrual control. Most progestogens are subjected to the first pass effect of the liver, and they adversely affect the lipoprotein profile. However, when progestogens are added sequentially to oestrogens their potential for causing an atherogenic lipid profile is reduced. They are quickly eliminated, and daily doses are required. Progesterone and progestogens act by:

- Down-regulation of oestrogen receptor expression.

- Increasing the catabolism of oestradiol.

- Inhibition of oestradiol mediated oncogene transcription.

The duration of progestogen use rather than its dose seem to be the important factor in the secretory transformation of the endometrium. However, higher doses of the progestogen may be required to improve cycle control, but this may also increase the incidence and severity of premenstrual tension type of symptoms.

TIBOLONE

This is a synthetic steroid, described to have a combination of activities including weak oestrogenic, weak progestogenic, and weak androgenic actions. It may be used alone as a supplement for postmenopausal women to reduce vasomotor symptoms and to reduce postmenopausal bone loss. The rate of increase in BMD is estimated at about $1.5 \%-2 \%$ over two years of use, and therefore is less effective than oestrogen. It may help to alleviate vasomotor symptoms without causing mastalgia, but is also associated in some women with the development of bloating, fluid retention, and psychological symptoms similar to those of premenstrual tension. It is an amenorrhoeic regimen and does not cause uterine bleeding in the majority of users. However, while the total cholesterol is reduced as a result of treatment, the HDL-cholesterol level is also reduced and more profoundly compared with the continuous combined HRT regimen. ${ }^{57}$ It is administered in a daily dose of $2.5 \mathrm{mg}$. It is indicated in women who have passed the menopause, who do not wish to bleed, or in those with contraindications to the use of oestrogen.

\section{RALOXIFENE}

Selective oestrogen receptor modulators are a family of compounds found to exert oestrogenic effects in certain body tissues but not others. Raloxifene, a non-steroidal benzothiaphene, is chemically related to tamoxifen. Both raloxifene and tamoxifen bind the oestrogen receptors and show mixed agonist and antagonist activity in different oestrogen responsive tissues. Both drugs reduce bone turnover and modulate hepatic globin synthesis, in a manner similar to oestrogen. Raloxifene, however, does not stimulate the uterus, unlike tamoxifen, which acts as a partial oestrogen agonist on the uterus. Raloxifene is metabolised by the liver and undergoes extensive enterohepatic cycling. Raloxifene is orally administered as a daily dose of $60 \mathrm{mg}$.

Raloxifene has been shown to reduce markers of bone turnover and may result in an increase of vertebral BMD by about $1.2 \%-$ $1.6 \%$ per annum, ${ }^{74}$ therefore it is less effective than oestrogen. However, there are no data directly comparing the two treatments. There appears to be no endometrial stimulatory effect of raloxifene compared with controls in terms of ultrasound measured endometrial thickness or the incidence of uterine bleeding. ${ }^{75}$ Raloxifene may reduce serum cholesterol and LDL-cholesterol levels, similar to HRT, but does not affect the HDL-cholesterol levels or triglycerides, which rise by $11 \%-20 \%$ with HRT. $^{76}$

Raloxifene seems to be devoid of breast stimulatory effect and claims have been made to a lower incidence of developing new breast cancers during treatment for up to three years. ${ }^{77}$ However, there is an increase in the incidence of vasomotor symptoms with raloxifene treatment. Also reported is an increased risk of thromboembolism, to the same extent as that of HRT, and development of leg cramps. Clearly this preparation is indicated in women who have passed the menopause, who do not complain of vasomotor symptoms, and who are at an increased risk of osteoporosis. It may prove useful in the prevention and treatment of osteoporosis, as an alternative to HRT, in women with oestrogen dependent neoplasia and those who do not wish to bleed.

\section{Compliance}

No more than $50 \%-60 \%$ of women on HRT will continue to take it beyond one year and one of the main causes of non-compliance with HRT in perimenopausal and postmenopausal women is withdrawal bleeding, particularly if irregular or heavy. Progestogenic side effects adversely affect compliance, but manipulation of the dose and type of the progestogen may 
help to ameliorate this problem. However, reducing the dose of the progestogen may jeopardise cycle control.

Unscheduled heavy bleeding with poor predictability of the day of onset has been documented to occur in as many as $50 \%$ of postmenopausal women using oestradiol $2 \mathrm{mg}$ daily with cyclical norethisterone $1 \mathrm{mg}$ /day, days $17-28$ of the treatment cycle. ${ }^{78}$ Such incidence is indeed prevalent among all cyclical combined HRT preparations in use. ${ }^{79}$ The cycle may be regulated by increasing the dose of progestogen, but this may increase the incidence of progestogen induced adverse effects.

Continuous combined HRT (progestogen along with oestrogen) has been suggested as an alternative to improve compliance as it is associated with a lower frequency of bleeding. Such regimens prevent bleeding as the progestogen maintains the endometrium in the thin and atrophic state. Nevertheless, $50 \%$ of women experience bleeding episodes during the first six months of treatment ${ }^{57}$ and about $40 \%$ discontinued treatment during the first year for a variety of reasons; including $8 \%$ due to unacceptable bleeding. This raises the issue of further investigation of the endometrium if bleeding continues beyond six months from commencement of continuous combined HRT, when it has to be considered as "postmenopausal bleeding" and investigated as such. Older women may be more suited to receive a low dose continuous combined HRT (oestradiol $1 \mathrm{mg}$ and norethisterone $0.5 \mathrm{mg}$ ), or it may be prescribed in those women who develop adverse effects on the standard dose of continuous combined HRT-for example, oestradiol $2 \mathrm{mg}$ with norethisterone $1 \mathrm{mg}$, or, conjugated equine oestrogens $(0.625 \mathrm{mg})$ with $2.5 \mathrm{mg}$ medroxyprogesterone.

Another important factor in the management of postmenopausal women on HRT is the finding of a twofold increase of abnormal bleeding in the presence of submucous fibroids, odd ratio $2.4,95 \%$ CI 1.25 to $4.53 .^{80}$ Whether the presence of these structural abnormalities reflects abnormal development of the vascular supply to the endometrium is not known. However, their hysteroscopic removal may rectify this problem in the vast majority of instances. ${ }^{81}$

Other factors that affect compliance include:

- Weight gain: increase in appetite is caused by the progestogen component of the HRT regimen and appropriate dietary advice should be given. Oestrogen induces redistribution of fat thus reducing the waist:hip ratio.

- Cancer phobia (see below).

\section{Risk of breast cancer}

Cancer of the breast is the second most common cancer in the female population of the Western world. Its incidence rises sharply between the age of 50 and 60. It is a multifactorial condition and its aetiological relationship to oestrogen therapy has been suggested but never proved. Fear of causality is the most commonly stated reason for discontinuation of HRT.
An increased relative risk of breast cancer in women receiving oestrogen replacement treatment, postulated to be around 1.33 (95\% CI 1.12 to 1.57 ), is shown in only one significant study, ${ }^{82}$ while refuted in many others. ${ }^{83-85}$ Further, data from the Leisure World follow up study showed that the risk of breast cancer mortality in oestrogen users was $0.81 .^{86}$ The addition of progestogens, sequential or continuous combined, to offset the endometrial effects of oestrogen, has not been shown to offer protection against breast cancer. ${ }^{87}$ Nevertheless, when counselling women who wish to start HRT, all these issues should be discussed. Women should be advised on breast self examination on monthly basis, and to have a breast examination annually by their doctor or practice nurse. Although this may result in increasing referrals to breast units with attendant anxieties while awaiting the results of investigations, it is in my view a fundamental part of the "breast awareness" campaign. Screening mammography is currently performed in the UK every three years between the ages of 50 to 64 , but $25 \%$ of interval cancers not identified at screening occur between the second and third year. Therefore particularly in high risk women, mammography is advised at least every two years. Data on mammographic screening, which were started at the age of 45 and performed at two years intervals, resulted in $25 \%$ reduction in mortality after 14 years of follow up. ${ }^{88}$ These data are in agreement with most meta-analyses of randomised trials. ${ }^{89}$

\section{Endometrial cancer}

The use of unopposed oestrogen, cyclically or continuously administered, promotes endometrial mitotic activity and can result in hyperplasia, complex hyperplasia, atypical hyperplasia, and early carcinoma of the endometrium. After one year of treatment the incidence of hyperplasia is increased to $20 \% .{ }^{90}$ The average time for progression of hyperplasia to carcinoma of the endometrium is about five years, and $25 \%-$ $30 \%$ of atypical hyperplasia progress to carcinoma within one year. ${ }^{91}$

In a recent case-control study from Sweden the relative risk of developing endometrial carcinoma after five or more years of use of unopposed oestrogen is markedly increased: for oestradiol (odds ratio $(\mathrm{OR})=6.2 ; 95 \%$ CI 3.6 to 12.0 ) and for conjugated equine oestrogens ( $\mathrm{OR}=6.6 ; 95 \%$ CI 3.1 to 12.6$)$. The use of cyclical progestin reduced the risk dramatically $(\mathrm{OR}=1.6 ; 95 \%$ CI 1.1 to 2.4$)$, but this risk increased in women who use the progestin for less than 16 days per cycle, most commonly 10 days per cycle $(\mathrm{OR}=2.9 ; 95 \% \mathrm{CI}=1.8$ to 4.6 for five or more years of use). Continuous progestin use along with oestrogens, on the other hand, was associated with a reduced risk $(\mathrm{OR}=$ $0.2 ; 95 \% \mathrm{CI}=0.1$ to 0.8 for five or more years of use). ${ }^{92}$

\section{Conclusion}

It should be emphasised that the menopause is a positive step in a woman's life, it is the beginning of the postreproductive phase of her life, 
when she may pursue a new career, education, or vocation. The symptoms of oestrogen deprivation can be relieved by oestrogen treatment, which if taken long term will help to prevent genital atrophy and reduce the risks of disabilities related to osteoporosis. There is increasing evidence for the role of HRT in reducing the risks of cardiovascular diseases. These issues highlight the importance of HRT and rank it among the most significant preventative public health programmes. The commitment to long term HRT, however, is not an easy decision for women, especially when they are asymptomatic. In order to enhance the acceptance of the preventative role of HRT in our ageing society, the woman must be given the opportunity to ask questions after adequate counselling, and the balance of risks and benefits have to be amply explained, such that she is enabled to make informed health choices.

1 Kaplun A, ed. Health promotion and chronic illness: discovering a new quality of health. World Health Organisation Regional Publications, European series, No 44. Geneva: WHO, 1992.

2 MacNaughton J, Banah M, McCloud P, et al. Age related MacNaughton J, Banah M, McCloud P, et al. Age related
changes in follicle stimulating hormone, luteinizing horchanges in follicle stimulating hormone, luteinizing hormone, oestradiol and immunoreactive inhibin in women

3 Faddy MJ, Gosden RG, Gougeon A, et al. Accelerated disappearance of ovarian follicles in mid-life: implications for forecasting menopause. Hum Reprod 1992;7:1342-6.

4 Faddy MJ, Gosden RG. A model conforming the decline in ollicle numbers to the age of menopause in women. Hum Reprod 1996;11:1484-6.

5 Taylor AH, Al-Azzawi F. The distribution of oestrogen receptors in the body. Mol Endocrinol 2000 (in press).

6 Bäckström T. Symptoms related to the menopause and sex steroid treatments. Ciba Found Symp 1995;191:171-86.

7 Luine VN, McEwen BS. Effect of oestradiol on turnover of type A monoamine oxidase in the brain. $\mathcal{F}$ Neurochem 1977; 28:1221-7.

8 Crowley WR. Effects of ovarian hormones on norepinephrine and dopamine turnover in individual hypothalamic and extra-hypothalamic nuclei. Neuroendocrinology 1982;34 381-6.

9 Paganini-Hill A, Henderson VW. Estrogen replacement therapy and risk of Alzheimer disease. Arch Intern Med 1996;156:2213-7.

10 Yaffe K, Sawaya G, Lieberburg I, et al. Estrogen therapy in postmenopausal women: effects on cognitive function and dementia. $\mathcal{F} A M A$ 1998;279:688-95.

11 Maheux R, Naud F, Rioux M, et al. A randomized, doubleblind, placebo-controlled study on the effect of conjugated estrogens on skin thickness. Am F Obstet Gynecol 1994;170: 642-9.

12 Ashcroft GS, Dodsworth J, van Boxtel E, et al. Estrogen accelerates cutaneous wound healing associated with an accelerates cutaneous wound healing associated with
increase in TGF-beta1 levels. Nat Med 1997;3:1209-15.

13 Cooper C. Femoral neck bone density and fracture risk. Osteoporos Int 1996;6(suppl 3):24-6.

14 Riggs B, Melton LJ III. Involutional osteoporosis. N Engl $\mathcal{f}$ Med 1986;314:1676-86.

15 Ott SM. Bone density in adolescents. $N$ Engl $\mathcal{F ~ M e d ~}$ 1991;325: $1646-7$.

16 Wark JD. Osteoporosis: pathogenesis, diagnosis, prevention and management. Bailliere's Clinical Endocrinology and Metabolism 1993;7:151-81.

17 Hui SL, Wiske PS, Norton JA, et al. A prospective study of change in bone mass with age in postmenopausal women. fournal of Chronic Diseases 1982;35:715-25.

18 Marshall D, Johnell O, Wedel H. Meta-analysis of how well measures of bone mineral density predict occurrence of measures of bone mineral density predict occu
osteoporotic fractures. BMF 1996;312:1254-9.

19 Galien R, Garcia T. Estrogen receptor impairs interleukin-6 expression by preventing protein binding on the NF-kappaB site. Nucleic Acids Res 1997;25:2424-9.

20 Hughes DE, Dai A, Tiffee JC, et al. Estrogen promotes apoptosis of murine osteoclasts mediated by TGF-beta. Nat Med 1996;2:1132-6.

21 Horowitz MC. Cytokines and estrogen in bone: antiosteoporotic effects. Science 1993;260:626-7.

22 Tiegs RD, Body JJ, Wahner HW, et al. Calcitonin secretion in postmenopausal osteoporosis. N Engl f Med 1985;312 in postmen.

23 Chen C, Noland KA, Kalu DN. Modulation of intestinal vitamin D receptor by ovariectomy, estrogen and growth
hormone. Mech Ageing Dev 1997;99:109-22.

24 Hans D, Dargent-Molina P, Schott AM, et al. Ultrasonographic heel measurements to predict hip fracture in elderly
women: the EPIDOS prospective study. Lancet 1996;348: 511-4.
25 Glüer CC. Quantitative ultrasound techniques for the assessment of osteoporosis: expert agreement on current assessment of osteoporosis: expert agreement on current status. The International Quantitative Ultraso
sus Group. $\mathcal{F}$ Bone Miner Res 1997;12:1280-8.

26 Colditz GA, Willett WC, Stamfer MJ, et al. Menopause and the risk of coronary heart disease in women. $N$ Engl $f$ Med 1987;316:1105-10

27 Stampfer MJ, Colditz GA. Estrogen replacement therapy and coronary heart disease: a qualitative assessment of the epidemiological evidence. Prev Med 1991;20:47-63.

28 Grady D, Rubin SM, Petitti DB, et al. Hormone therapy to prevent disease and prolong life in postmenopausal women [see comments]. Ann Intern Med 1992;117:1016-37.

29 Voutilainen S, Hippeläinen $M$, Hulkko S, et al. Left ventricular diastolic function by Doppler echocardiography in relation to hormonal replacement therapy in healthy postmenopausal women. Am f Cardiol 1993;71:614-7.

30 Pines A, Fisman EZ, Shemesh J, et al. Menopause-related changes in left ventricular function in healthy women. Cardiology 1992;80:413-6.

31 Pines A, Fisman EZ, Levo Y, et al. Menopause-induced changes in left ventricular wall thickness. Am f Cardiol 1993;72:240-1.

32 Villecco AS, de Aloysio D, de Liberali E, et al. High blood pressure and 'ischaemic' ECG patterns in climacteric women. Maturitas 1985;7:89-97.

33 Staessen J, Bulpitt CJ, Fagard R, et al. The influence of menopause on blood pressure. F Hum Hypertens 1989;3: $427-33$.

34 Botting R, Vane JR. The receipt and despatch of chemical messengers by endothelial cells. In: Schoor K, Sinzinger JR, eds. Prostaglandins in clinical research. New York: Alan R Liss, 1989: 1-11.

35 Collins P, Rosono GMC, Jiag C, et al. Cardiovascular protection by oestrogen-a calcium antagonist effect? protection by oestrogen

36 Mugge A, Riedel M, Barton $M$, et al. Endothelium independent relaxation of human coronary arteries by $17 \beta$
oestradiol in vitro. Cardiovasc Res 1993;27:1939-42.

37 Crane MG, Marris JJ, Windsor W. Hypertensive contraception agents and oestrogens. Ann Intern Med 1971;74:13-21

38 Wren BG, Routledge DA. Blood pressure changes oestrogen in climacteric women. Med $\mathcal{F}$ Aust 1981;ii:528-31.

39 Pfeffer RI, Kurosaki TT, Charlton SK. Estrogen use of blood pressure in later life. Am F Epidemiol 1979;11:469-78.

40 Lip GYH, Beevers M, Churchill D, et al. Hormone replacement therapy and blood pressure in hypertensive women. $f$ Hum Hypertens 1994;8:491-4.

41 Campbell S, Whithead MI. Oestrogen therapy and the menopausal syndrome. Clin Obstet Gynecol 1977;4:31-47.

42 Akkad A, Halligan AW, Abrams K, et al. Differing responses Akkad A, Halligan AW, Abrams K, et al. Differing responses
in blood pressure over 24 hours in normotensive women receiving oral or transdermal estrogen replacement therapy. Obstet Gynecol 1997;89:97-103.

43 Pines A, Fisman E Z, Levo Y, et al. The effects of hormone replacement therapy in normal postmenopausal women: measurement of Doppler derived parameters of aortic flow. Am f Obstet Gynecol 1990;164:806-12.

44 Volterrani M, Rosano G, Coats A, et al. Estrogen acutely increases peripheral blood flow in postmenopausal women. Am f Med 1995;99:119-22.

45 Gangar KF, Vyas S, Whitehead M, et al. Pulsatility index in internal carotid artery in relation to transdermal oestradiol and time since menopause. Lancet 1991;338:839-42.

46 Rosano GM, Sarrel PM, Poole-Wilson PA, et al. Beneficial effect of oestrogen on exercise-induced myocardial ischaemia in women with coronary artery disease. Lancet mia in women

47 Chester AH, Jiang C, Borland JA, et al. Oestrogen relaxes human epicardial coronary arteries through nonendothelium-dependent mechanisms. Coron Artery Dis 1995;6:417-22.

48 Rodriguez G, Warkentin S, Risberg J, et al. Sex differences in regional cerebral blood flow. $\mathcal{F}$ Cereb Blood Flow Metab 1988;8:783-9.

49 Penotti M, Nencioni T, Gabrielli L, et al. Blood flow variations in internal carotid and middle cerebral arteries induced by postmenopausal hormone replacement therapy. Am F Obstet Gynecol 1993;169:1226-32.

50 Akkad A, Hartshorne T, Bell PR, et al. Carotid plaque regression on oestrogen replacement: a pilot study. Eur $\mathcal{F}$ Vasc Endovasc Surg 1996;11:347-8.

51 Thompson GR. The proving of the lipid hypothesis. Current Opin Lipidol 1999;10:201-5.

52 Scanu AM. Lipoprotein(a). A genetic risk factor for premature coronary heart disease. $7 A M A$ 1992;26:3326-9.

53 Nabulsi AA, Folsom AR, White A, et al. Association of hormone-replacement therapy with various cardiovascular risk factors in postmenopausal women. The Atherosclerosis Risk in Communities Study Investigators. $N$ Engl f Med 1993;328: 1069-75.

54 Manson JE, Rimm EB, Colditz GA, et al. A prospective study of postmenopausal estrogen therapy and subsequent incidence of non-insulin-dependent diabetes mellitus. Ann Epidemiol 1992;2:665-73.

55 Folsom AR, McGovern PG, Nabulsi AA, et al. Changes in plasma lipids and lipoproteins associated with starting or stopping postmenopausal hormone replacement therapy. Atherosclerosis Risk in Communities Study. Am Heart $\dot{f}$ 1996;132:952-8.

56 Tikkanen MJ, Kuusi T, Nikkilä EA, et al. Post-menopausal hormone replacement therapy: effects of progestogens on
serum lipids and lipoproteins. A review. Maturitas 1986;8:717. 
57 Al-Azzawi F, Wahab M, Habiba $\mathrm{M}$, et al. A clinical and metabolic study of continuous combined hormone replace-
ment therapy compared to tibolone. Obstet Gynecol 1999;93: 258-64.

58 Folsom AR, Wu KK, Davis CE, et al. Population correlates of plasma fibrinogen and factor VII, putative cardiovascular risk factors. Atherosclerosis 1991;91:191-205

59 Heinrich J, Sandkamp M, Kokott R, et al. Relationship of ipoprotein(a) to variables of coagulation and fibrinolysis in a healthy population. Clin Chem 1991;37:1950-4.

60 Scarabin PY, Bonithon-Kopp C, Bara L, et al. Factor VII activation and menopausal status. Thromb Res 1990;57:22734

61 Meade TW. Hormone replacement therapy and haemostatic function [published erratum appears in Thromb Haemost 1997;78:1304]. Thromb Haemost 1997;78:765-9.

62 Low GDO. Coagulation, fibrinolysis, and hormone replacement therapy. In: Show RW, ed. Oestrogen deficiency: causes
and consequences. Carnforth: Parthenon, 1996: 29-44.

63 Jick H, Derby LE, Myers MW, et al. Risk of hospital admission for idiopathic venous thromboembolism among users of postmenopausal oestrogens. Lancet 1996;348:981-3.

64 Daly E, Vessey MP, Hawkins MM, et al. Risk of venous thromboembolism in users of hormone replacemen therapy. Lancet 1996;348:977-80.

65 Grady D, Applegate W, Bush T, et al. Heart and estrogen/progestin replacement study (HERS): design, methods, and baseline characteristics. Control Clin Trials 1998;19:314-35.

66 Hulley S, Grady D, Bush T, et al. Randomised trial of estrogen plus progestin for secondary prevention of coronary heart disease in postmenopausal women. $7 A M A$ 1998;280 605-13.

67 Adams MR, Register TC, Golden DL, et al. Medroxyprogesterone acetate antagonizes inhibitory effects of conjugated equine estrogens on coronary artery atherosclerosis. Arterioscler Thromb Vasc Biol 1997;17:217-21.

68 Miyagawa K, Rösch J, Stanczyk F, et al. Medroxyprogesterone interferes with ovarian steroid protection against coronone interferes with ovarian steroid protection against coron-
ary vasospasm [see comments]. Nat Med 1997;3:324-7.

69 Rosendaal FR, Siscovick DS, Schwartz SM, et al. A common prothrombin variant $(20210 \mathrm{G}$ to $\mathrm{A})$ increases the isk of myocardial infarction in young women. Blood 997;90:1747-50.

70 Navot D, Rosenwaks Z, Margalioth EJ. Prognostic assessment of female fecundity. Lancet 1987;ii: $645-7$.

71 Winslow KL, Toner JP, Brzyski RG, et al. The gonadotropin-releasing hormone agonist stimulation test - a sensitive predictor of performance in the flare-up in vitro fertilization cycle. Fertil Steril 1991;56:711-7.

72 Gulekli B, Bulbul Y, Onvural A, et al. Accuracy of ovarian reserve tests. Hum Reprod 1999;14:2822-6.

73 Smith DC, Prentice R, Thompson DJ, et al. Association of exogenous estrogen and endometrial carcinoma. $N$ Engl Med 1975;293:1164-7.

74 Delmas PD, Bjarnason NH, Mitlak BH, et al. Effects of raloxifene on bone mineral density, serum cholesterol concentrations, and uterine endometrium in postmenopausal women. N Engl f Med 1997;337:1641-7

75 Lufkin EG, Whitaker MD, Nickelsen T, et al. Treatment of established postmenopausal osteoporosis with raloxifene: a randomized trial. F Bone Miner Res 1998;13:1747-54
76 Walsh BW, Kuller LH, Wild RA, et al. Effects of raloxifene on serum lipids and coagulation factors in healthy postmenopausal women. $\mathscr{F} A M A$ 1998;279:1445-51.

77 Ettinger B, Black DM, Mitlak BH, et al for the Multiple Outcomes Raloxifene Evaluation (MORE) Investigators. Reduction of vertebral fracture risk in postmenopausa women with osteoporosistreated with raloxifene: results from a 3-year randomized clinical trial. $\mathcal{F A M A ~ 1 9 9 9 ; 2 8 2 :}$ $637-45$.

78 Habiba MA, Bell SC, Abrams K, et al. Endometrial responses to hormone replacement therapy: the bleeding pattern. Hum Reprod 1996;11:503-8.

79 Al-Azzawi F, Hawley J, Parsons A, et al. Investigation of the bleeding patterns of postmenopausal women treated with Estrapak-50. Maturitas 1994;18:115-25.

80 Akkad A, Habiba MA, Ismail N, et al. Abnormal uterine bleeding on hormone replacement: the importance of intrauterine structural abnormalities. Obstet Gynecol 1995; $86: 330-4$.

81 Al-Azzawi F, Kelada E, Wahab M, et al. Prediction of successful outcome following hysteroscopic laser myomectomy in women with heavy and unscheduled bleeding. Climacteric 1999;2(suppl 1):289.

82 Colditz GA, Stampfer MJ, Willett WC, et al. Type of postmenopausal hormone use and risk of breast cancer: 12 -year follow-up from the Nurses' Health Study. Cancer Causes Control 1992;3:433-9.

83 Wingo PA, Layde PM, Lee NC, et al. The risk of breast cancer in postmenopausal women who have used estrogen replacement therapy. $\mathscr{f} A M A$ 1987;257:209-15.

84 Kaufman DW, Palmer JR, de Mouzon J, et al. Estrogen replacement therapy and the risk of breast cancer: results from the case-control surveillance study. Am $\mathcal{F}$ Epidemiol 1991;134:1375-401.

85 Palmer JR, Rosenberg L, Clarke EA, et al. Breast cancer risk after estrogen replacement therapy: results from the Toronto Breast Cancer Study. Am f Epidemiol 1991;134:1386-401.

86 Henderson BE, Paganini-Hill A, Ross RK. Decreased mortality in users of estrogen replacement therapy. Arch Intern Med 1991;151:75-8.

87 Colditz GA, Egan KM, Stampfer MJ. Hormone replacement therapy and risk of breast cancer: results from ment therapy and risk of breast cancer: results from 80.

88 Alexander FE, Anderson TJ, Brown HK, et al. 14 years of follow-up from the Edinburgh randomised trial of breastcancer screening. Lancet 1999;353:1903-8.

89 Kerlikowske K, Grady D, Rubin SM, et al. Efficacy of screening mammography. A meta-analysis. $\mathscr{f} A M A$ 1995; 273:149-54.

90 Woodruff JD, Pickar JH. Incidence of endometrial hyperplasia in postmenopausal women taking conjugated estrogens (Premarin) with medroxyprogesterone acetate or conjugated estrogens alone. The Menopause Study Group [see comments]. Am 7 Obstet Gynecol 1994;170:1213-23.

91 Kurman RJ, Kaminski PF, Norris HJ. The behavior of endometrial hyperplasia. A long-term study of untreated hyperplasia in 170 patients. Cancer $1985 ; 56: 403-12$.

92 Weiderpass E, Adami HO, Baron JA, et al. Risk of endometrial cancer following estrogen replacement with and without progestins. $\mathcal{F}$ Natl Cancer Inst 1999;91:1131-7. 